\title{
Computing of Truss Structure Using MATLAB
}

\author{
Alžbeta Bakošová1, Jan Krmela ${ }^{1}$, Marián Handrik ${ }^{2}$ \\ ${ }^{1}$ Faculty of Industrial Technologies in Púchov, Alexander Dubček University of Trenčín. Ivana Krasku 491/30, \\ 02001 Púchov. Slovak Republic.E-mail: alzbeta.bakosova@student.tnuni.sk, jan.krmela@tnuni.sk \\ ${ }^{2}$ Faculty of applied mechanics, University of Žilina. Univerzitná 1, 01026 Žilina. Slovak Republic. E-mail: ma- \\ rian.handrik@fstroj.uniza.sk
}

Trusses are commonly used structure in industrial buildings, warehouses, bridges, transmission tower etc. The analysis of the truss structure design is necessary in order to ensure stable and economical system. This paper presents application for computing planar truss structures that was programmed in environment of MATLAB App Designer using finite element method (FEM). App Designer is programming environment used for creating computing applications with graphical user interface (GUI). The created application for trusses allows users to create geometrical model of the truss structure and input material data, perform static analysis, modal analysis and to optimize truss structure in order to minimize its weight. To ensure accuracy of results, test calculations was performed using commercial software and compared with results from the created application.

Keywords: Truss, MATLAB, Finite element method

\section{Introduction}

MATLAB is a programming environment, with its own programming language specializing in scientific and numerical computing. It also offers tools for FEM calculations like Partial Differential Equation Toolbox that provides features for solving static analysis [1], heat transfer, and general partial differential equations using FEM (MathWorks, 2019c). There are several books that deal with creating codes for FEM analysis in MATLAB, e.g. books: [2 - 5]. Application for computing planar truss structures was programmed in environment of App Designer that is part of MATLAB. The application is divided into 4 tabs: Geometry model, Static analysis, Modal analysis and Optimization. The first Geometry model contains elements of GUI for creating model of truss system and entering input data. The tab Static analysis allows running the FEM analysis and then displaying the results of displacements, stresses, and so on. The Modal Analysis tab is used to calculate eigenvalues and modal shapes, and the tab Optimization allows the optimization of the cross-sections and shape of truss system in order to reduce weight.

\section{Methods}

Truss structures constitute a special class of structures, in which individual members are straight bars connected at joints that permit rotation. It is designed to take only axial forces, therefore it deforms only in its axial direction. The cross-section of the bar can be arbitrary, but the dimensions of the cross-section should be much smaller than that in the axial direction. Finite element equations for truss elements are described in [4]. The equation (1) is solved, where $K$ is global stiffness matrix. Stiffness matrix for truss element for truss element $k_{e}$ equals (2).

$$
\begin{gathered}
K U=F[N] \\
k_{e}=\frac{A_{e} E}{l_{e}}\left[\begin{array}{cc}
1 & -1 \\
-1 & 1
\end{array}\right]\left[N^{-1}\right]
\end{gathered}
$$

Where $U$ is vector of displacements, $F$ vector of forces, $A_{\mathrm{e}}$ is area of element cross section, $l_{e}$ is its length and $E$ is Young's modulus.

The vibration analysis is an important stage in the design of mechanical systems and buildings subject to dynamic loads. Modal analysis [6] is used to study the inherent vibration characteristics of a structure including natural frequencies and normal modes (shapes). In modal analysis equation (3) is solved [7].

$$
\boldsymbol{M} \ddot{\boldsymbol{U}}+\boldsymbol{K} \boldsymbol{U}=\mathbf{0}[\boldsymbol{N}]
$$

Where $M$ is mass matrix. There are several methods for mass matrix composition, they are described in [8]. Direct Mass Lumping method was used in our application. In this method total mass of element is directly apportioned to nodal freedoms, ignoring any cross coupling. A key motivation for direct lumping is that a diagonal mass matrix may offer computational and storage advantages. For truss element mass matrix $M_{L} e_{L}$ is expressed in equation:

$$
M_{L}^{e}=\frac{1}{2} \rho A_{e} l_{e}\left[\begin{array}{ll}
1 & 0 \\
0 & 1
\end{array}\right][k g] .
$$

Where $\varrho$ is density.

For optimization of truss system was used a function from the MATLAB optimization toolbox fmincon. This function looks for a minimum of bounded 
nonlinear multivariate problem and it is described in MATLAB documentation [9]. Fully Stress Design algorithm was used to optimize truss cross-sections. It is described in [10].

\section{Application for computing truss structu- res programmed in MATLAB}

In the Fig. 1 is GUI of the tab geometrical model. To create nodes, it is necessary to enter the number of the node and its $\mathrm{X}$ and $\mathrm{Y}$ coordinates in the respective editable boxes and then click on the add button (fields marked with number 1 in the Fig. 1). There are also buttons for editing and deleting nodes. The specified nodes and their coordinates are listed above these buttons. To create truss element it is required to enter number of the truss, numbers of its nodes and the area of its cross section (fields 2). When adding force, the force number, the number of the node, where the force acts and the size of the force components along $\mathrm{x}$ and $\mathrm{y}$ axis are needed (fields 3 ). To remove degree of freedom (DOF) it is possible to create fixity by entering its number, number of the node in which is DOF removed and choose whether the motion is free or fixed in direction of $\mathrm{x}$ and $\mathrm{y}$ axes (fields 4).In the bottom of GUI is line with information for user (marked 5), e.g. error warnings. In the graphical representation of the truss system, it is possible to select whether nodes, node numbers, trusses and their numbers, forces (shown by a black arrow), numerical values of forces, constraints and the angle of inclination of constraint are shown by selecting the checkboxes. Material data are entered in fields 7. It is possible to select units (checkboxes 6) and save, load and clear model with buttons labelled 8 .

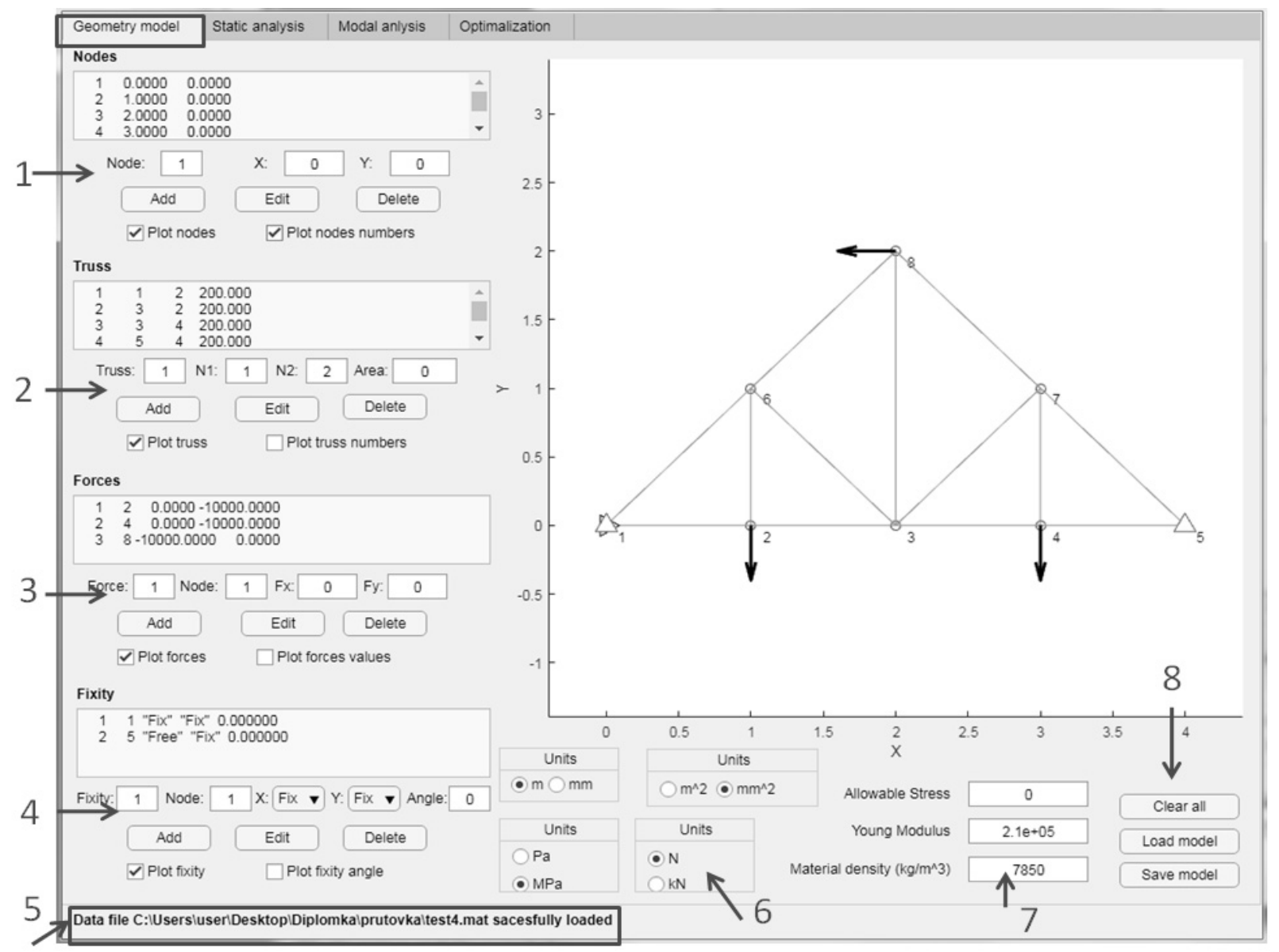

Fig. 1 GUI for creating model of truss structure

The $2^{\text {nd }}$ tab Static analysis is in the Fig. 2. The calculation of the static analysis can be started by clicking on the button Calculate, which is marked 1 in the figure. Nodal displacement, truss force, stress and strain and reaction in fixity are calculated. Numerical results displayed in the window marked 6 can be selected by clicking on the relevant option in the selection field List results (marked 2). Graphical representation of results selected in the selection field Plot results (marked 3) is shown in window 7 . When displaying displacement of nodes, scale can be set by slider marked 4. The truss system without deformation is drawn by a green line, deformed by a dashed blue line. Similar to the tab Geometry model, by clicking on the respective check boxes (marked 8 in Fig. 2) it is possible to select whether to display nodes, truss, their numbers, constraints, etc. 


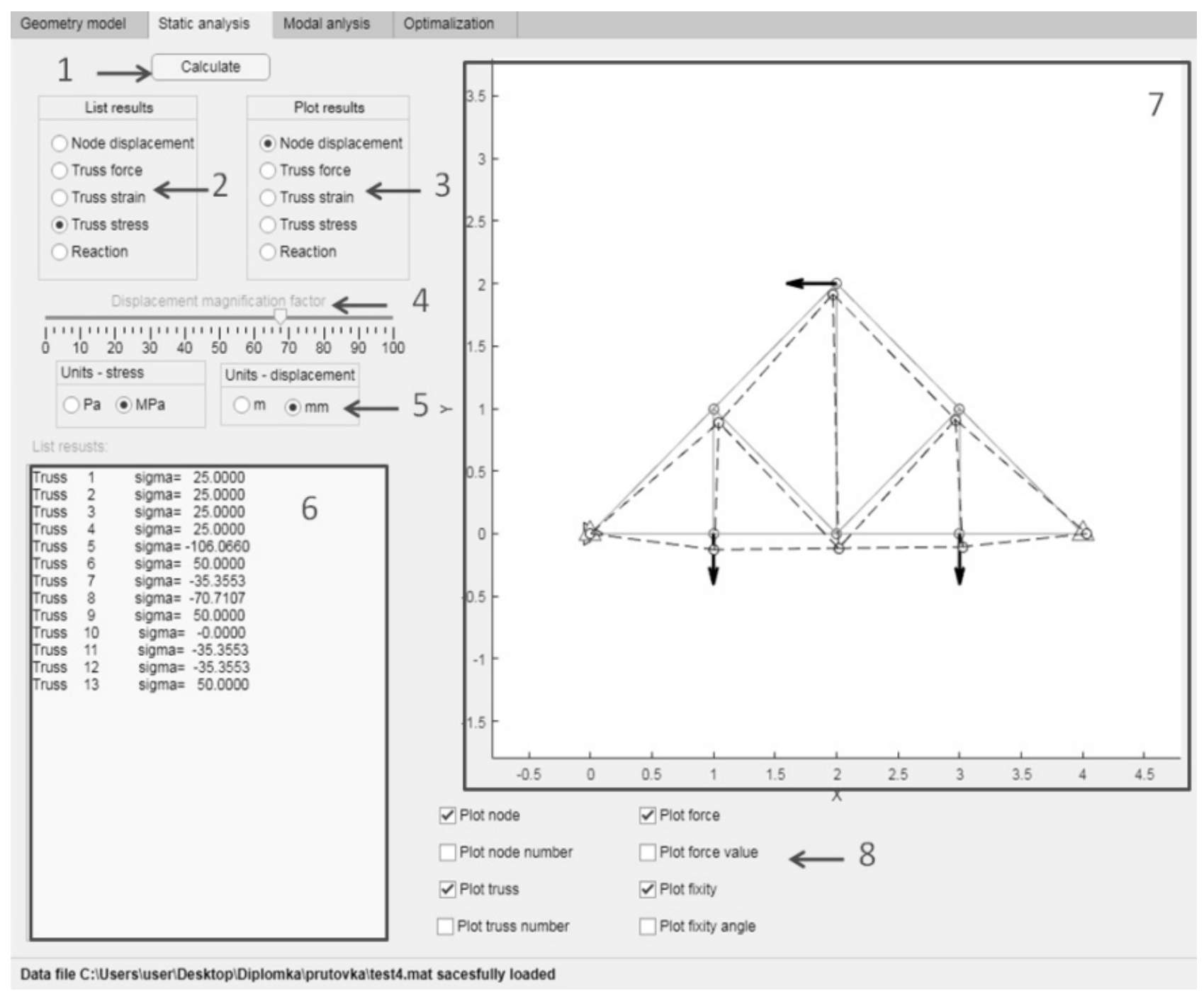

Fig. 2GUI of the tab for static analysis of the programmed application

In Fig. 3 is a graphical representation of reaction forces (magenta arrows) and truss forces. The tension is shown by blue arrows, the compression by red ones.
Stress and strain are shown in the same way as the truss forces.
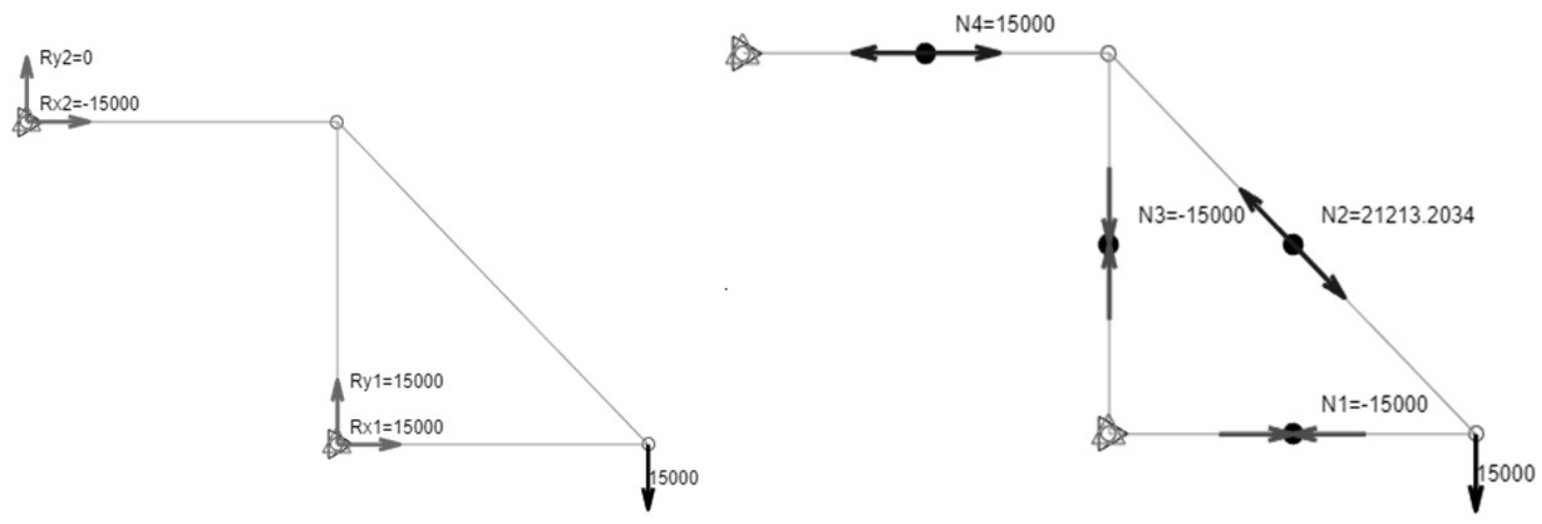

Fig. 3 Graphical representation of reaction forces and truss forces

The user interface of the tab Modal analysis is shown in the Fig. 4. As with the static analysis, the calculation is started by clicking on the button Calculate (marked 1). After the calculation, the natural frequencies $[\mathrm{Hz}]$ are listed in window 2. In window 3 there is a graphical representation of the truss structure and its 
modal shapes. The number of the modal shape that is display is entered in the box Mode labelled 5. Slider bar (marked 4) is used to change the scale of deflection. Pressing the button 6 starts the system oscillation animation. Similar to the Geometry model tab, by clicking on the respective check boxes (marked 7), it can be selected what is displayed and at the bottom there is a row with user information.

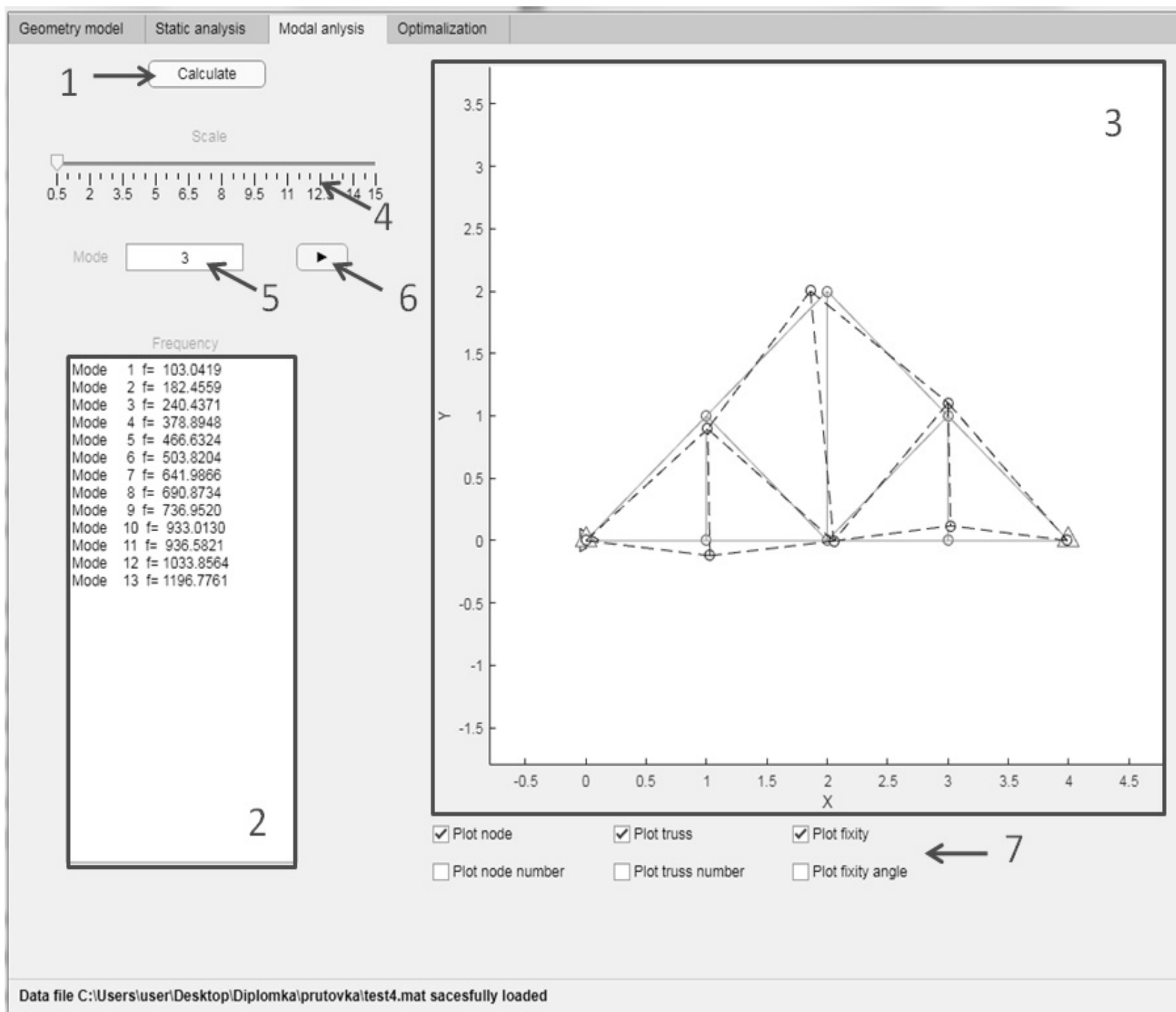

Fig. 4 GUI for modal analysis

In the Fig. 4 there is the user interface of the tab for optimization in order to reduce weight of the truss system. The application allows to choose whether only the cross-section of trusses will be optimized (option Cross sections in the selection field marked 1 in Fig. 4) or also the geometry of the truss system (option Cross sections and geometry). It is also possible to set groups of trusses with the same cross-section (in table marked 2), nodes of the truss system whose position will be optimized and maximum change of coordinates of these nodes (fields labelled 3). Clicking on the button Calculate (marked 4) starts the calculation. After calculation is completed, the resulting coordinates of nodes are listed in window 5) and the resulting truss cross-sections in window 6 . Original and optimized weight is displayed in fields 7. It is also possible to display the results of the static analysis of the optimized truss system by selecting the quantity from the selection fields List Results, which are marked 8 in the Fig. 5. The original and optimized truss system can be plotted in the window for graphical representation of the results. The original system is shown in green, the graphical elements of this system that we want to display are selected from the check boxes in column marked 9. The optimized system is drawn in red and the check boxes are grouped in column marked 10 . For the optimized system, displacement can be displayed by ticking check box labelled 11, the scale of these displacements can be changed using the slider bar above this checkbox. This tab also contains a row with information for the user. 


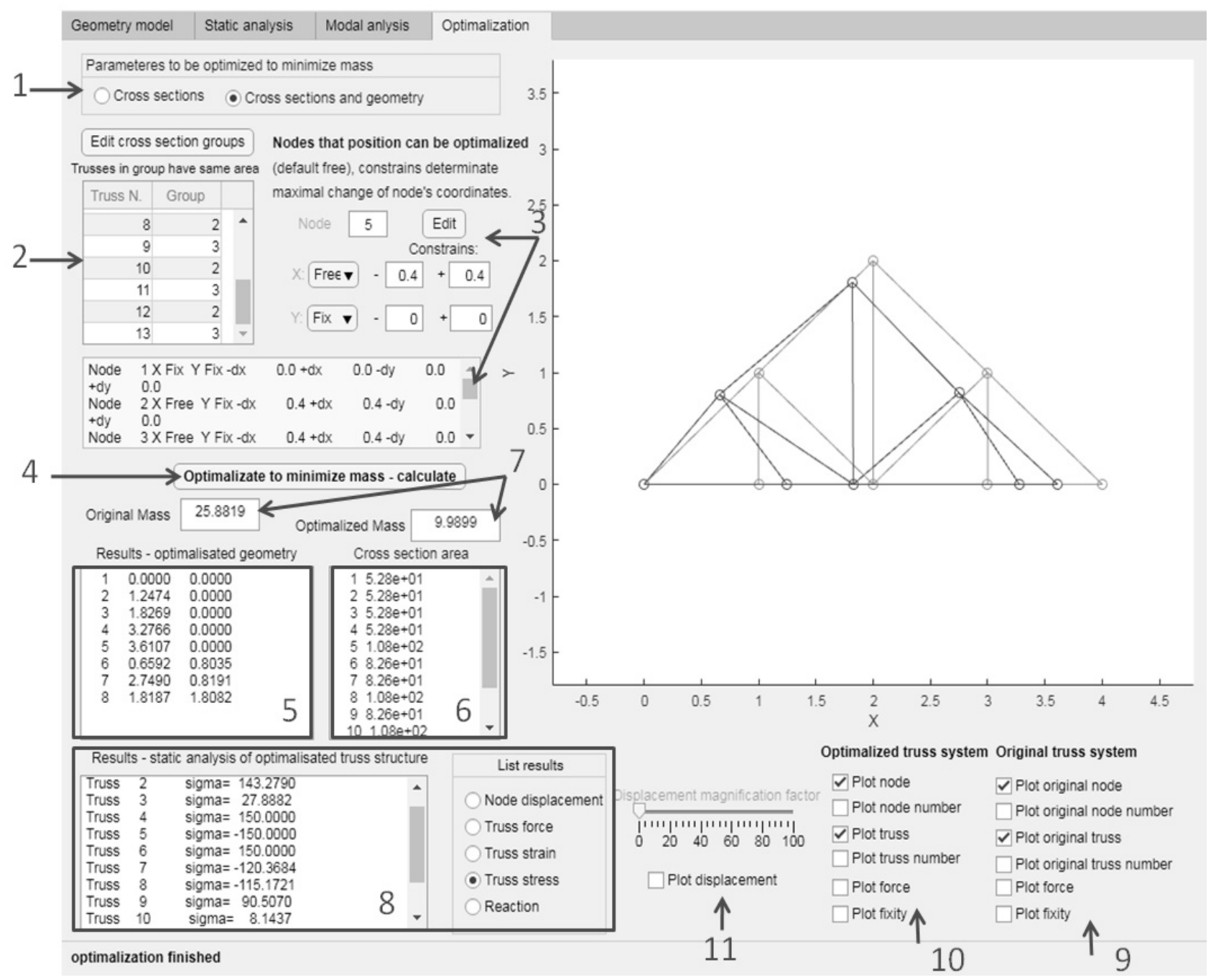

Fig. 5 GUI for optimization of truss structure

\section{Testing of the application and results}

The accuracy of the results was verified by calculation of several test problems and comparison with results from commercial software ANSYS. The truss system, which geometry is shown in the Fig. 6 is example of tested structures that was solved. In node 1 there is the rotational constraint in nodes 2 and 3 there are a rotational-sliding constraints, with a free displacement in the $x$-axis direction. Force $F_{1}$ equal to $5000 \mathrm{~N}$ is applied in node 3 and force $F_{2}$ equal to 8000 $\mathrm{N}$ is applied in node 4. The allowable stress is 150 $\mathrm{MPa}$. The cross-sections of all bars have an area of 100 $\mathrm{mm}^{2}$, Young's modulus is $2.1 \times 10^{5} \mathrm{MPa}$, density is 7850 $\mathrm{kg} . \mathrm{m}^{-3}$. Then shape and cross-section of the truss system was optimized. Cross section was uniform for all trusses. The boundaries within which the coordinates of each node can change was set: node 1 was set as fixed, nodes 2 and 4 could change in both directions within $\max \pm 200 \mathrm{~mm}$ and a node 3 could change within $\pm 400 \mathrm{~mm}$.

Firstly, the static analysis was performed. The results from ANSYS matched the results from our
MATLAB application and they were same as mathematically exact solution. The results are listed in Tab. 1

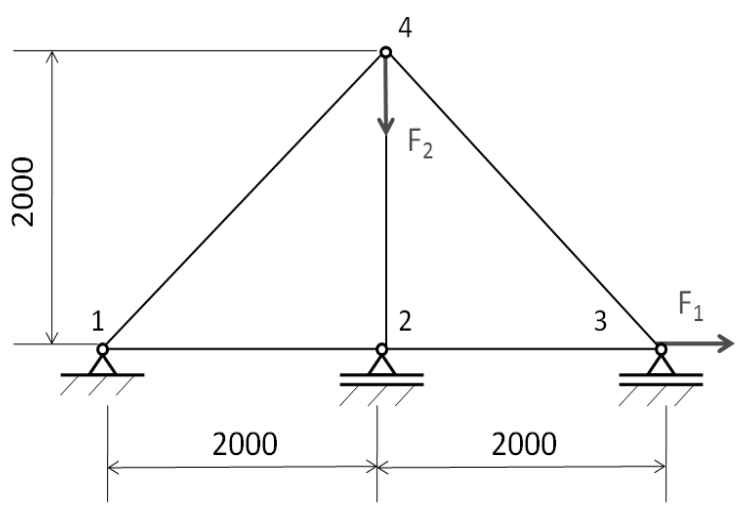

Fig. 6 Truss structure used for verification of results

The results of the modal analysis also coincided, but it was necessary to set the same method of mass matrix formation. The natural frequencies and modal shapes are shown in the Fig. 7.. 
Tab. 1 Results of the static analysis

\begin{tabular}{|c|c|c|c|c|}
\hline Truss & Truss force [N] & Deformation 10-4 [-] & Stress [MPa] & $\begin{array}{c}\text { Reaction force in } \\
\text { constrains [N] }\end{array}$ \\
\hline $1-2$ & 5514.72 & 2.63 & 55.1472 & $\mathrm{R} 1 \mathrm{x}=-5000$ \\
\hline $1-4$ & -727.92 & -0.35 & -7.2792 & $\mathrm{R} 1 \mathrm{y}=514.72$ \\
\hline $2-4$ & -6970.56 & -3.32 & -69.7056 & $\mathrm{R} 2 \mathrm{y}=6970.56$ \\
\hline $2-3$ & 5514.72 & 2.63 & 55.1472 & $\mathrm{R} 3 \mathrm{y}=514.72$ \\
\hline $3-4$ & -727.92 & -0.35 & -7.2792 & - \\
\hline
\end{tabular}

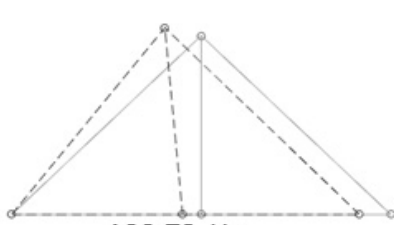

$188.73 \mathrm{~Hz}$

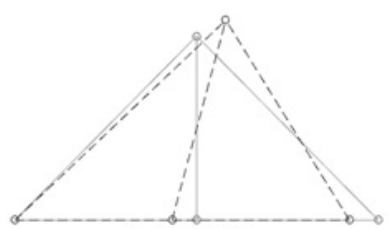

$305.77 \mathrm{~Hz}$

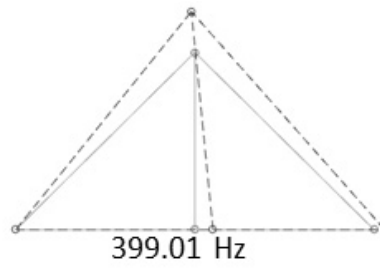

$399.01 \mathrm{~Hz}$

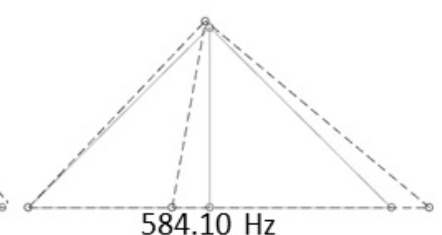

$584.10 \mathrm{~Hz}$

Fig. 7 Results of static analysis

The results of the optimization are shown in the Tab. 2. For optimization using ANSYS the screening method was used to generate a set of samples and sort them based on target parameters (in this case, weight) and constraints (maximum allowable stress). It is a non-iterative approach that is available for all types of input parameters [11]. This method is usually used for preliminary design. Then the Nonlinear Programming by Quadratic Lagrangian method was used for better optimization results [12]. The optimized weight obtained in ANSYS was slightly higher $(0.18 \mathrm{~kg})$ than from our application. The difference is caused by different optimizing methods.

Tab. 2 Comparison of optimization results

\begin{tabular}{|c|c|c|c|c|c|c|}
\hline \multicolumn{7}{|c|}{ Ansys } \\
\hline Node & 1 & 2 & 3 & 4 & Weight & $3.76 \mathrm{~kg}$ \\
\hline Coordinate X & $0 \mathrm{~mm}$ & $1813 \mathrm{~mm}$ & $3602.4 \mathrm{~mm}$ & $1876.1 \mathrm{~mm}$ & Maximal stress & $-1.48 \mathrm{MPa}$ \\
\hline Coordinate $\mathrm{Y}$ & $0 \mathrm{~mm}$ & $-29.16 \mathrm{~mm}$ & $-48.41 \mathrm{~mm}$ & $2490.6 \mathrm{~mm}$ & Cross Section & $63.62 \mathrm{~mm}^{2}$ \\
\hline \multicolumn{7}{|c|}{ Application created in MATLAB } \\
\hline Node & 1 & 2 & 3 & 4 & Weight & $3.58 \mathrm{~kg}$ \\
\hline Coordinate X & $0 \mathrm{~mm}$ & $2004.14 \mathrm{~mm}$ & $3600.18 \mathrm{~mm}$ & $1971.92 \mathrm{~mm}$ & Maximal stress & $-1.50 \mathrm{MPa}^{2}$ \\
\hline Coordinate Y & $0 \mathrm{~mm}$ & $-49.33 \mathrm{~mm}$ & $-30.64 \mathrm{~mm}$ & $2216.95 \mathrm{~mm}$ & Cross Section & $39.3 \mathrm{~mm}^{2}$ \\
\hline
\end{tabular}

\section{Conclusions}

Using the FEM, one can usually expect only an approximated solution. However, we obtained the exact solution for truss structure. This is because the exact solution of the deformation for the truss is a first order polynomial. The shape functions used in this FEM analysis are also first order polynomials that are constructed using complete monomials up to the first order. Therefore, the exact solution of the problem is included in the set of assumed displacements in FEM shape functions. For truss elements that are free of body forces, there is no need to use higher order elements, as the linear element can already give the exact solution. However, for truss members subjected to body forces arbitrarily distributed in the truss elements along its axial direction, higher order elements can be used for more accurate analysis. The procedure for developing such high order one-dimensional elements is the same as for the linear elements. The only difference is the shape functions. For further development of this application this type of load could be included. It also would be beneficial to expand analysis to enable to solve not just planar but also spatial problems.

\section{Acknowledgement}

This paper deal was supported by project KEGA $037 \not ̌ U-4 / 2018$,Implementation of effective computational tools into modern information and communication technologies with the aim of increasing competencies of graduates of technical 
studies" and project KEGA 002TnUAD-4/2019 „The influence of temperature and other parameters on the tensile properties of polymer composites and polymers under the uniaxial and biaxial cyclic loading".

\section{References}

[1] SOUKUP, J., KRMELA, J., KRMELOVÁ, V., SKOČILASOVÁ, B., ARTYUKHOV, A. (2019). FEM Model of Structure for Weightlifting in CrossFit in Terms of Material Parameters. In: Manufacturing Tecbnology. Vol. 19, No. 2, pp. $321-326 . \quad$ ISSN 1213-2489. DOI: 10.21062/ujep/290.2019/a/12132489/MT/19/2/321

[2] BANG, H. - KWON, Y. W. (2000). The finite element method using MATLAB. CRC Press. ISBN: 08493-0096-7.

[3] KATTAN, P. I. (2010). MATLAB guide to finite elements: an interactive approach. Springer Science \& Business Media. ISBN: 978-3-540-70697-7.

[4] FERREIRA, A. (2008). MATLAB codes for finite element analysis: solids and structures. Springer Science \& Business Media. ISBN: 978-1-40209199-5.

[5] RAGAB, S. A.; FAYED, H. E. (2017). Introduction to Finite Element Analysis for Engineers. CRC Press. ISBN 978-1-1380-3017-6.

[6] KOVÁČIKOVÁ, P., VAVRO, J., VAVRO jr., J., DUBEC, A. (2018). Microstructure Evaluation of Ductile Cast Iron and Numerical Modal
Analysis. In: Manufacturing Technology. Vol. 18, No. 4, pp. 597 - 599. ISSN 1213-2489. DOI: 10.21062/ujep/144.2018/a/1213$2489 / \mathrm{MT} / 18 / 4 / 597$

[7] SÁGA, M., VAŠKO, M., HANDRIK, M., KOPAS, P. (2019). Contribution to random vibration numerical simulation and optimisation of nonlinear mechanical systems. In: Scientific Journal of Silesian University of Technology. Series Transport, Vol. 103, pp. 143 - 154.

[8] FELIPPA, C., GUO, Q., PAR, K. C. (2014). Mass Matrix Templates: General Description and 1D Examples. In: Archives of Computational Methods in Engineering. Vol. 22, No. 1, pp. 1 - 65.

[9] MATHWORKS (2019). MATLAB Documentation. [Online]. Retrieved from: $<$ https://uk.mathworks.com/help/matlab/>.

[10] GIL, L., ANDREU, A. (2000). Shape and cross-section optimisation of a truss structure. In: Computers and Structures. Vol. 79, pp. 681 689.

[11] XIAOLIN, CH., YIJUN L. (2015). Finite Element Modeling and Simulation with ANSYS Workbench. Boca Raton: CRC Press. ISBN: 978-14398-7385-4.

[12] SÁGA, M., VAŠKO, SÁGOVÁ Z., HANDRIK, M. (2018). Effective algorithm for structural optimization subjected to fatigue damage and random excitation. In: Scientific Journal of Silesian University of Technology. Series Transport. Vol. 99., pp. 149 - 161. 